\title{
Educación religiosa escolar en perspectiva liberadora ${ }^{1}$
}

\section{School religious education in a liberating perspective}

Recibido: 10 de marzo de 2014 - Revisado: 8 de enero de 2015 - Aceptado: 13 de abril de 2015

José Luis Meza Rueda² - Gabriel Suárez Medina ${ }^{3}$

Juan Alberto Casas Ramírez ${ }^{4}$ - Daniel de Jesús Garavito Villarreal ${ }^{5}$

David Eduardo Lara Corredor ${ }^{6}$ - José Orlando Reyes Fonseca ${ }^{7}$

\section{Resumen}

La educación religiosa en Colombia, de acuerdo con la ley 115 de 1994, es un área de formación fundamental. Sin embargo, su propósito de promover la dimensión religiosa del ser humano y comprender el papel de la religión en la cultura está lejos de ser alcanzado porque, en la práctica, se considera como un área de segundo orden, está desarticulada del currículo y funciona aún como la "clase de religión” de tiempos pasados. ¿Qué hacer frente a esto? ¿Será posible otra manera de pensar la educación religiosa? Estimamos que, como los presupuestos y motivaciones tanto de la teología de la liberación como de la pedagogía liberadora siguen vigentes en nuestros días, estos pueden brindar pistas al respecto. En consecuencia, este escrito no solo hace una lectura detallada a esta realidad en algunas instituciones educativas oficiales de Colombia, sino que también da luces para que la educación religiosa escolar (ERE) sea liberadora.

\section{Palabras clave}

Educación religiosa liberadora, teología de la liberación, pedagogía liberadora, investigación acción crítica reflexiva, formación religiosa.

\begin{abstract}
Religious education in Colombia, according to Law 115 of 1994, is an area of fundamental training. However, its purpose of promoting the religious dimension of human beings and understanding the role of religion in culture is far from being achieved, because, in practice, it is considered as an area of second order, is disjointed from the curriculum and is still working as the "religion lesson" of the past. What to do against this? Could it be another way of thinking about religious education? We estimate that, as presuppositions and motivations of both liberation theology and liberating pedagogy are still valid today, they may provide clues in this respect. Consequently, this paper not only makes a detailed reading of this reality in some official educational institutions in Colombia, but also sheds light for the school religious education (ERE) to be liberating.
\end{abstract}

\section{Keywords}

Liberating religious education, liberation theology, liberating pedagogy, reasearch, reflexive critical action, religious training.
${ }^{1}$ Artículo producto de investigación "Hacia una educación religiosa escolar liberadora. Elementos liberadores presentes en la educación religiosa escolar en algunas instituciones educativas oficiales de Colombia", ciones educativas oficiales de Colombia", del Grupo de Investigación Didaskalia, veriana, Bogotá, Colombia.

veriana, Bogotá, Colombia. Ph. D. y M.Sc. en Teologia, Pontificia Universidad Javeriana; magister en Docencia, Universidad de La Salle, especialista en Educación Sexual, Fundación Universitaria Monserrate, especialista en Desarrollo Humano y Social, IPX-Madrid; licenciado en Educación con especialidad en Estudios Religiosos, Universidad de La Salle. Profesor e investigador de la Pontificia Universidad Javeriana, Bogotá, Colombia.

Correo electrónico:

joseluismeza@javeriana.edu.co

${ }^{3} \mathrm{Ph}$. D. en Filosofia, Pontificia Universidad Gregoriana, Roma. Licenciado en Educación, Filosofia y Letras, Universidad Santo Tomás, teólogo de la Universidad Pontificia Salesiana Roma; licenciado en Teología, Pontificia Universidad Javeriana; especialista en Docencia Universitaria, Universidad Santo Tomás. Profesor asociado e investigador de la Pontifici Universidad Javeriana Bogoté Cola Pontificia Correo electrónico:

gs000123@javeriana.edu.co

${ }_{4}^{4}$ Ph.D. (C). en Teología. Magíster en Teología, licenciado en Ciencias Religiosas y diplomado en Pastoral Educativa Académica y en mado en Pastoral Educativa Academica y en
Espiritualidad de la Docencia Universitaria de la Pontificia Universidad Javeriana. Docente la Pontificia Universidad Javeriana. Docente
investigador de la Facultad de Teología de diinvestigador de la Facultad de Teologia de di-
cha universidad. Tiene estudios en Filosofia y Teología del Seminario Mayor de Bogotá, en Lenguas bíblicas del Instituto Bíblico Pastoral Latinoamericano (IBPL) de la Corporación Universitaria Minuto de Dios y en Historia de las Religiones del Centro de Estudios Teológicos y de las Religiones (Cetre) de la Universidad del Rosario.

Correo electrónico:

jcasas.smsj@javeriana.edu.co

${ }^{5}$ M.Sc. en Filosofia y Msc. en Teología. Ph. D.

(C). en Teología de la Pontificia Universidad

Javeriana Licenciado en Educación, especiaJaveriana. Licenciado en Educacion, especialidad en Ciencias Sociales de la Universidad Libre de Colombia. Estudios en Filosofia y Teología, Seminario Regional Juan XXIII. Profesor investigador de la Facultad de Teologia y coordinador del area de Teología de la Acción Humán. Pontificia Universidad Javeriana, Bogotá, Colombia. Correo electrónico: garavitod@javeriana.edu.co

${ }^{6}$ M.Sc. en Teología. Especialista en Derechos Humanos; investigador de la Pontificia Universidad Javeriana, Bogotá, Colombia. Correo electrónico: delara@javeriana.edu.co ${ }^{7} \mathrm{Ph}$. D. (C). en Teología; licenciado y Msc. en Teología, Msc. en Educación de la Pontificia Universidad Javeriana; especialista en Docencia Universitaria, Universidad El Bosque. Investigador de la Pontificia Universidad Javeriana, Bogotá, Colombia. Correo electrónico: jose.reyes@javeriana.edu.co

Para citar este artículo: Meza, J., Suárez, G., Casas, J., Garavito, D., Lara, D., \& Reyes., J. (2015). Educación religiosa escolar en perspectiva liberadora. Revista Civilizar Ciencia. Sociales y Humanas, 15(28), 247-262. 


\section{Introducción}

La educación religiosa escolar (ERE) es considerada por la Ley General de Educación (ley 115 de 1994, art. 23) como un área fundamental y, por su objeto, está llamada a contribuir con el propósito de formación integral que procura la escuela a través del desarrollo de la dimensión religiosa del sujeto y la comprensión de lo religioso como componente de la cultura (Suárez, Meza, Garavito, Lara, Casas \& Reyes, 2013, p. 221). Ahora bien, en un contexto como el colombiano, la ERE no puede ser aséptica ni indiferente a las realidades y dinámicas sociales. Es aquí donde adquiere pertinencia la perspectiva liberacionista que, por ser profética, crítica y utópica, podría darle a la ERE una naturaleza y dinamismo diferentes a aquella que pretende salvaguardar el statu quo religioso.

En otras palabras, la ERE ha de promover una toma de conciencia de la realidad histórica en la que se encuentran los educandos impulsándoles a trascenderla a través de una mirada crítica y una opción liberadora (p. 221). Una de las claves para hacerlo es la ubicación sobre la realidad misma en la cual nos hallamos, realidad caracterizada por la pobreza, exclusión, violencia, ignorancia y explotación. Otra clave es de carácter prospectivo: pensar que otro mundo es posible y, por tanto, evidenciar la actualidad del principio de liberación.

En los últimos años se vienen dando diferentes propuestas de ERE tanto de forma local como regional. Un buen número de instituciones educativas -muchas de ellas regentadas por comunidades religiosas- se ha sumado a las directrices de la Conferencia Episcopal de Colombia (CEC) y ha constituido una ERE análoga a la catequesis escolar. Otras instituciones han asumido diseños que le dan primacía a la ilustración religiosa o han permutado la formación religiosa por asuntos propios de la ética, la axiología y la ciudadanía. $\mathrm{Y}$ otro número de instituciones sencillamente renunció a pensar la ERE y sigue impartiendo lo que se conocía como clase de Religión. Las entidades oficiales no se libran de este panorama $\mathrm{y}$, por la misma razón, se convirtieron en motivo de esta pesquisa (Suárez et al., 2013, p. 221).

Por lo anterior, la investigación de la cual trata el presente artículo, intentó dar respuesta a la pregunta: ¿qué elementos liberadores se identifican en la ERE de algunos centros educativos oficiales en Colombia? El problema así planteado, encerraba la posibilidad de encontrar, con algún grado de intensidad, rasgos que podrían ser correspondientes con los planteamientos de la teología de la liberación y la pedagogía liberadora, vertientes de reflexión propias de nuestra América. Y, a partir de estos mismos referentes, nos propusimos establecer unos lineamientos para promover una ERE liberadora.

En términos generales, la ERE, en cuanto "religiosa" se apoya disciplinarmente en la teología y las ciencias de la religión, y en cuanto “educación", en la pedagogía y la didáctica. No obstante, para el caso de una ERE liberadora, aquellas no pueden inscribirse en cualquier horizonte epistemológico; antes bien, resulta congruente que sean la teología de la liberación y la pedagogía liberadora las que den luces a la hora de pensar su naturaleza teórica y práctica.

Por último, esta investigación quiso dar cuenta del carácter teológico del acto educativo y de la fundamentación teológica y pedagógica de la ERE para suscitar auténticas dinámicas liberadoras en los contextos educativos del país. Además, si el objeto de estudio de la teología es la revelación, como acontecer comunicativo y salvífico de Dios en la historia, y la fe como respuesta transformadora $y$ liberadora del ser humano a dicha revelación, la ERE debería brindar a los estudiantes las claves hermenéuticas para reconocer dicha revelación en su propio contexto y los criterios práxicos para responder a la misma desde el entorno social en el que se desenvuelven. 


\section{Antecedentes}

Una revisión minuciosa de diferentes bases de datos nos permitió constatar un interés creciente por la educación religiosa ${ }^{1}$. Los estudios encontrados muestran diversas aproximaciones de comunicación teológica y su enseñabilidad en la escuela, ya en el nivel primario o secundario. Sin embargo, también evidenciamos la inexistencia de investigaciones acerca de una ERE en clave de liberación, excepción hecha de un trabajo escrito por Eileen Bellett (1998) con el título Religious education for liberation: a perspective from Paulo Freire, en el cual la autora hace una reflexión en torno al influjo de la categoría freiriana "concientización" en el vocabulario teológico y educativo. De forma particular, Bellett se detiene en la relación de la propuesta del arzobispo de York, John Habgood, en la que habla de una educación religiosa que se caracteriza por la solidaridad crítica y lo expuesto por el mismo Freire en algunas de sus obras.

Por otra parte, se identificaron algunos trabajos próximos al problema de investigación por el diálogo estrecho entre teología de la liberación y pedagogía liberadora. En los años setenta, Joaquín Panini y Hugo Hidalgo (1975) publicaron un opúsculo con el título Educación liberadora. Dimensión pastoral. Con la dinámica propia del ver-juzgar-actuar, los autores hacen un diagnóstico de la sociedad, establecen algunos criterios antropológicos, sociológicos y teológicos de la evangelización, y presentan una propuesta para transformar la escuela desde una perspectiva comunitaria.

De forma más reciente, se encuentran los trabajos de Matthias Preiswerk (1994) Educación popular y teología de la liberación, y Fernando Torres (1999) Por caminos propios: construcción pedagógica de la teología popular. Preiswerk (1994), en cuanto teólogo y pedagogo, genera un diálogo entre la teología de la liberación y la educación popular en cinco pasos: aprender a aprender, aprender a analizar, aprender a interpretar, aprender a comunicar y aprender a transformar. Él entiende la educación popular como una de las "formas de militancia" en las que se lucha con la palabra. Esa palabra que no repite las alocuciones de los otros, sino que descubre la realidad, que la renueva, que la transforma; pero también, es la palabra que libera al sujeto.

Para Torres (1999) la educación popular y la teología de la liberación son parte de la historia de América Latina. Cuando se entrecruzan en su sentido, es posible descubrir una "teología pedagógica popular" y la "pedagogización del saber teológico" capaz de fundamentar la pedagogía que transcurre en el hecho teológico popular. Este diálogo propicia lo que el autor llama una "subjetividad teológica popular", resultado de categorías eminentemente liberadoras como: identidad y alteridad, concientización y empoderamiento, diálogo y solidaridad, y contemplación y acción.

\section{Marco teórico}

La ERE, desde un propósito general, favorece el desarrollo integral de la persona, el logro de su propia autonomía y el de su identidad personal y social (Garcés, García \& Medarda, 1998) y, desde un propósito particular, promueve las dimensiones espiritual y religiosa en el sujeto en relación con la cultura, la sociedad y la religión. La ERE liberadora asume este cometido y, sin embargo, también espera que el sujeto forme un pensamiento reflexivo, analítico y crítico sobre los problemas religiosos de su realidad; sepa dar sentido a la existencia última de su vida; integre fe y vida en lo cotidiano; establezca relaciones dialógicas con los otros; en últimas, que viva su vocación a través de su propia humanización y la humanización del mundo. No obstante, para lograr lo anterior, es necesario romper con una visión individualizada de la educación porque la persona, si lo es, es gracias al vínculo con los otros, con su contexto y con el mundo (Suárez et al., 2013, p. 222). 
Ahora bien, la realidad religiosa no puede pensarse ajena a la realidad global; si aquella merece un cambio, esta también. Mejor aún, el cambio que pueda ocurrir en la primera supone que algo ha sucedido en la segunda. ¿Quién dudaría de que se esté requiriendo, hoy más que nunca, de una transformación de las estructuras injustas de la sociedad, de sus convicciones o de los egocentrismos individuales y colectivos que generan insensibilidad frente a las necesidades de los sujetos y las naciones? (Suárez et al., 2013, p. 223).

La realidad sufriente de hombres y mujeres de América Latina, palpable y lamentable, clama por un cambio que no vendrá mágicamente. Este será el resultado de un proceso en el cual la educación tendrá un papel protagónico y transformador. Nuestro continente necesita de una educación que promueva, en los niños y jóvenes, una mentalidad de "sociedad pluralista" (Boff \& Murano, 2004). Con esta, se evitaría cualquier tipo de fragmentación, subordinación y exclusión, como el machismo, la xenofobia, el totalitarismo, el conformismo, el etnocentrismo, entre otros. El reto no es minúsculo pero tampoco es nuevo. La segunda Conferencia del Episcopado Latinoamericano (CELAM) (1968) ya señalaba el indicador de una educación liberadora: convertir "al educando en sujeto de su propio desarrollo" (p. 49).

Empero, si el educando se hace sujeto de su propio desarrollo, es porque se ha concientizado de su sí-mismo-en-relación-con $\mathrm{y}$, por tanto, podrá llevar a cabo la tarea de humanizar humanizando la realidad social en la que vive. Concientizar es entonces "educar para leer el mundo" con ojos críticos, de modo que se busque la liberación mediante el rechazo a la dependencia, la opresión y la marginación (Suárez et al., 2013, p. 224).

Por el contrario, si la educación no conduce al desarrollo de una conciencia crítica, capaz de llevar a la persona a un estado de libertad, es una mera transmisora de un compendio de temas sin contacto con el mundo, ni con la realidad de marginación que se debe transformar. Según Freire (citado por Bandera, 1991), este tipo de educación es "necrófila, depositaria, bancaria, estomacal, digestiva, domesticadora, adormecedora, o sea, todo lo contrario de lo que debe proponerse un buen educador" (p. 12). En cambio, la concientización se desarrolla en el nivel de conciencia crítica:

La conciencia es, en este sentido, test de la realidad. Cuando mayor es la concientización, más desvela la realidad, más se penetra en la esencia fenomenológica del objeto frente al cual uno se encuentra para analizarlo. Por esta razón, la concientización no consiste en estar frente a la realidad, asumiendo una posición falsamente intelectual; la concientización no puede existir fuera de la praxis, es decir sin el acto acción-reflexión. Esta unidad dialéctica constituye, de manera permanente, el modo de ser o de transformar el mundo que caracteriza a los hombres (p. 69).

Por ser la conciencia un principio de transformación del mundo, la concientización implica un compromiso histórico. Una conciencia volcada sobre el mundo por medio de la acción-reflexión es una conciencia comprometida, que actúa sobre el mundo como sujeto: "Ser sujeto de la historia mediante el proceso de concientización quiere decir que el hombre tiene la historia en sus manos, porque es él quien la impulsa, la hace y la rehace, transformándola sin cesar" (Freire, citado por Bandera, 1991, p. 71).

Entonces, una ERE, si es liberadora, está llamada a transformar la situación de los oprimidos en tanto produce conciencia del estado en el que se vive y apunta a una liberación gradual, pero total del hombre oprimido. Este cambio no se queda en un ámbito individual; también tiene impacto grupal, local y regional: "Una liberación de las estructuras no es posible ni durable sin la mediación de una auténtica liberación de las conciencias" (Sanz, 1985, p. 239). 
Una educación liberadora es por esencia dialogal y afectiva. Según Freire (2010, p. 107), el método apropiado de la pedagogía de la liberación -y de cualquier empresa humana- es el diálogo, cuya fuerza reside en el amor, la fe, la humildad, la confianza y la esperanza. El diálogo es esencial para cambiar el mundo y sus realidades de opresión. Igualmente, la educación liberadora solo es posible si se realiza una opción fundamental por el amor en beneficio de los oprimidos, porque el amor es entendido como compromiso con el oprimido, es decir, con seres humanos concretos, en favor de quienes hay que optar.

En particular, si la ERE hace una lectura en profundidad de la experiencia religiosa, de lo vivido en el ámbito del Misterio y de la apertura a lo trascendente, ha de mostrar al sujeto que en una "verdadera" experiencia religiosa acontece la apertura a la dimensión trascendente del otro, porque en él está totalmente el Otro. Una ERE liberadora no se contenta con religar al ser humano con el Absoluto, porque sabe que este reduccionismo solo produce intimismos y espiritualismos individualistas.

Al contrario, una ERE liberadora promueve la religación interna del sujeto -que supera la fragmentación cuerpo-alma-espíritu a la cual lo ha abocado Occidente-, pero también la religación con las otras personas (porque es polis, comunidad, tribu) y con el mundo (porque es kosmos, tierra, materia). Así las cosas, una ERE liberadora hace caer en cuenta al sujeto que la religación que conlleva una experiencia religiosa no lo enajena, no lo aliena, ni le niega su libertad (Suárez et al., 2013, p. 226).

Una ERE liberadora pretende la "concienciación"” del sujeto, su liberación, su humanización, la opción por el pobre y la valoración de su propia cultura y de su historia como condición de una experiencia religiosa auténtica. La ERE liberadora, a diferencia de la ERE bancaria que promueve una conciencia ingenua, comprende que "la concientización es tanto la interpretación de la experiencia del oprimido y de la sociedad que genera la opresión, como el reconocimiento de la necesidad de un compromiso para transformar dicha realidad" (Preiswerk, 1994, p. 46). Para lograrlo, el educador explicita esta realidad, ayuda a interpretarla y acompaña la acción transformadora. En la ERE liberadora la persona se humaniza, humanizando el mundo:

[...] el sujeto debe educarse para realizarse como persona integralmente, pero esta realización no puede darse al margen de su grupo, de su comunidad concreta; liberándose y desarrollándose con los otros, en comunidad: construyendo una comunidad más humana se va construyendo simultáneamente él como hombre (Sanz, 1985, p. 247).

\section{Diseño metodológico.}

El método que guió la investigación fue el de la acción crítica reflexiva (ACR), fundada en el paradigma crítico-reflexivo (Fals-Borda, 1978; 1992; Lewin, 1992). Dicho paradigma reconoce que es posible el cambio de los contextos -junto con el de los sujetos individuales y colectivos- siempre y cuando se dé cuenta de la dialéctica presente entre el ser y el deber ser. Por eso, durante todo el proceso fue de suma importancia la reflexión en cada etapa, como queda expresado en la gráfica 1 .

\section{Gráfica 1. \\ Dinámica de la investigación acción crítica reflexiva}

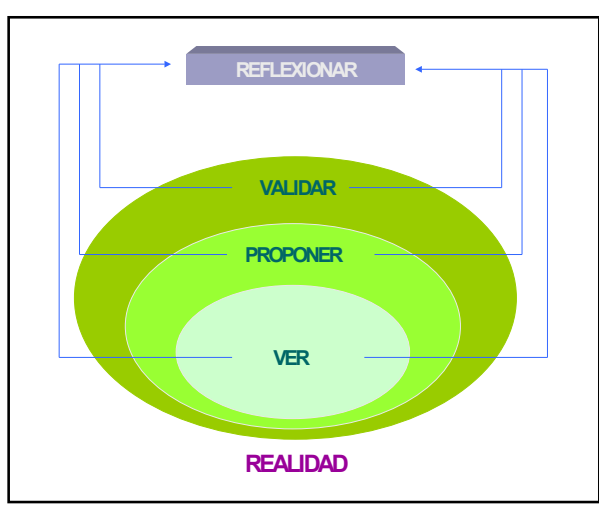

Fuente: elaboración propia con base en Fals-Borda $(1978,1992)$ y Lewin (1992). 
Este método de investigación, como bien lo afirma Arellano (2010), promueve la participación activa de la comunidad, tanto en el estudio y la comprensión de sus problemas, como en la planeación de propuestas de acción, su ejecución, la evaluación de los resultados, la reflexión y la sistematización del proceso seguido. Para nuestro caso, este método nos ayudó a comprender cómo ocurre la ERE en las instituciones educativas participantes y, una vez evaluadas a la luz de la perspectiva teológica y pedagógica liberadoras, se hizo una propuesta (lineamienta) para favorecer una formación religiosa dentro de esta perspectiva.

Además, como el método elegido tiene un talante crítico-reflexivo, se procuró en su dinámica y diseño técnico-instrumental una reflexión acerca de lo que se hace junto con el cómo, porqué se hace y para qué se hace la ERE en las respectivas instituciones. Tal reflexión quiso constituirse en un camino para reencontrarse con la "liberación" como eje fundante de la educación en nuestro continente. Siguiendo a Arellano (2010), las fases de la investigación fueron las que presenta la gráfica 2 .

Gráfica 2.

Fases del método de investigación acción crítica reflexiva

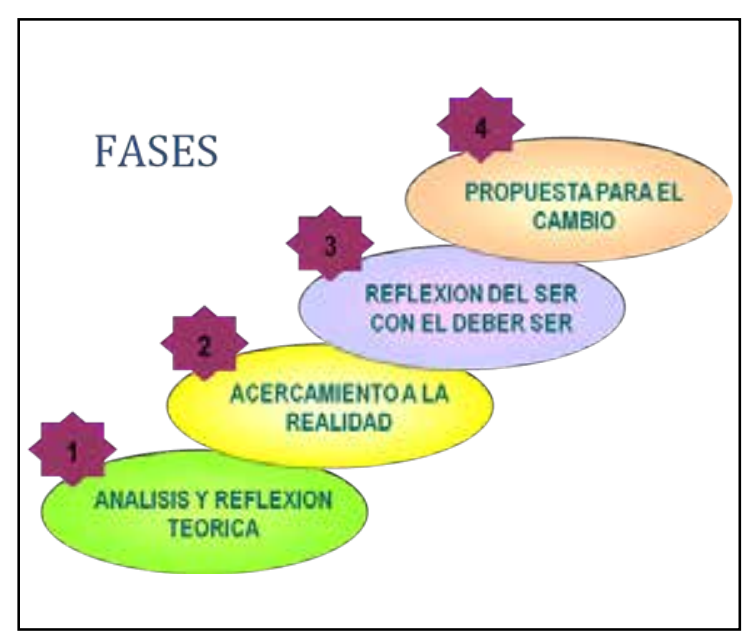

Fuente: elaboración propia con base en Arellano (2010).

\section{Fase 1. Análisis y reflexión teórica.}

En esta etapa se estableció la fundamentación epistemológica para estudiar el problema. Los postulados de los representantes y estudiosos de la teología de la liberación y de la pedagogía liberadora, junto con los de la ERE, nos brindaron los elementos para exponer lo propio de una ERE liberadora como su concepto, propósito y notas esenciales, fines y dimensiones, principios y mediaciones, entre otros aspectos. El resultado de esta fase se publicó en un libro con el nombre Educar para la libertad. Una propuesta de educación religiosa escolar en perspectiva liberadora (Meza \& Suárez, 2013).

\section{Fase 2. Acercamiento a la realidad de las comunidades educativas.}

Aquí se identificó lo que está ocurriendo en la ERE en cada institución. En esta etapa se privilegiaron la entrevista semiestructurada, la entrevista a grupos focales y la revisión documental -proyecto educativo institucional (PEI), planes de área, programas de asignatura y los cuadernos de la clase de educación religiosa-. La entrevista semiestructurada se aplicó a profesores de educación religiosa y la entrevista a grupos focales a estudiantes de $6^{\circ}$ y $10^{\circ}$ grado. Las preguntas de los respectivos guiones pretendían indagar sobre la finalidad de la ERE, sus dimensiones, objeto de estudio, principios, mediaciones, contenidos, didáctica, evaluación e integración con el currículo.

\section{Fase 3. Reflexión del ser con el de- ber ser}

Partiendo de lo que dijera Rosental:

Los hombres mismos crean su historia pero no pueden hacerlo a su capricho, pues cada nueva generación actúa en determinadas condiciones objetivas creadas con anterioridad a ella... Estas condiciones y las leyes que rigen partiendo de ellas, ofrecen múltiples posibilidades y, por tanto, el discurrir real de la histo- 
ria, depende de los hombres, de su actividad y su iniciativa, del grado de organización y cohesión de las fuerzas progresistas (citado en Hurtado, 1998, p. 36)

Nos preguntamos por la brecha existente entre el ser y el deber ser. De esta forma se estableció un camino para una ERE en clave liberadora en las instituciones educativas participantes.

\section{Fase 4. Reflexión y construcción de la propuesta.}

En esta fase se elaboraron unos lineamientos teológico-pedagógicos para promover una ERE en clave de liberación que fuera pertinente a la realidad de los centros educativos. Por el método elegido, fue necesario llevar a cabo diversos encuentros con las comunidades educativas (especialmente con estudiantes, profesores y directivos) para socializar y discutir los avances dados hasta llegar a un consenso.

Las catorce instituciones educativas participantes eran de carácter oficial y, en su mayoría, estaban ubicadas en la periferia social y geográfica de nuestro país. Estas se encuentran en los departamentos de Bolívar, Norte de Santander, Nariño y Putumayo 3 .

\section{Resultados}

Como ya se dijo, a la luz de la teología y la pedagogía liberacionistas, se estableció lo propio de una ERE liberadora. En la primera fase se definieron sus categorías constitutivas, a saber: principios, dimensiones, mediaciones, contenidos, didácticas, evaluación, comunidad educativa, finalidad, legitimación, objeto de estudio e integración curricular. Tales categorías nos permitieron dar cuenta del problema de investigación y constituir, a partir de los datos recolectados, una propuesta que fuera pertinente para las instituciones participantes. En su orden, encontramos lo siguiente:

\section{Principios.}

Los principios de una ERE liberadora son: encarnación, pluralidad e inclusión, fe crítica y desprivatizada, misericordia y esperanza (Boff, 1990, p. 104; Meza \& Suárez, 2013, p. 148). Al rastrear la información de las instituciones, se pudo evidenciar que ni en las formulaciones ni en la práctica, hay afinidad con los principios de una ERE liberadora. Más aún, estos se confunden con los contenidos que se ofrecen en los programas de ERE.

Algunas instituciones centran los principios en la comprensión de la formación integral y la democracia, tales como la responsabilidad, el respeto, la tolerancia y la honestidad. En una de las instituciones se señala que el foco del proceso educativo es el estudiante y se educa para el respeto de las opiniones de los demás, con una participación activa que permita integrar a la comunidad y propender por el desarrollo de la misma, fomentando la autonomía. En otra se asumen principios democráticos de justicia, tolerancia, solidaridad, participación y sentido de pertenencia; por ello en el PEI, los principios son homologables a los fundamentos legales, filosóficos, pedagógicos, antropológicos, axiológicos, epistemológicos, sociológicos y psicológicos. Uno de los colegios enuncia algunos principios asumidos desde una perspectiva liberadora como encarnación en la realidad, dignidad humana y promoción de los derechos humanos.

Otros centros educativos fundamentan los principios desde la perspectiva cristiana. En uno de ellos se reconocen prácticas de solidaridad e inclusión, acercamientos al principio de misericordia y concienciación del sujeto. En este sentido, se garantiza el respeto por las identidades religiosas y se promueve la fe, la amistad y la convivencia entre grupos religiosos. También se encontró una insistencia en los valores cristianos, la dimensión comunitaria del ser humano y el compromiso con los otros. 


\section{Dimensiones.}

Una ERE liberadora privilegia las dimensiones metanoica, histórica, de alteridad, ecológica, profética, utópica, anamnética y de sentido (Freire, 1989; Meza \& Suárez, 2013, p. 128). Una lectura holística de los datos no muestra estas dimensiones, no obstante, sí se insiste en algunos valores y actitudes que tienen correspondencia con los de una ERE liberadora. Se observa una sensibilidad marcada hacia lo ecológico, la alteridad y lo utópico. La dimensión histórica, como principio de la ERE, es tal vez la que se puede evidenciar con mayor fuerza.

Para una de las instituciones de Nariño la dimensión de alteridad es muy sólida en su propuesta, con una inclinación hacia lo utópico, la alteridad y el sentido de la vida. En otra ubicada en Putumayo, las dimensiones se expresan a través de las características que se proyectan en el perfil del estudiante: "Se pretende que al terminar su formación escolar, se identifiquen como personas íntegras, críticas, reflexivas [y] humanistas; capaces de tener su propia identidad, un proyecto de vida definido para su bienestar y el de su comunidad" (Archivo reservado, p. 9).

Los docentes aseguran que el aspecto fundamental, a partir del cual se aborda la clase, es la humanidad de cada uno, su libertad y su fe particular. Uno de los colegios cimienta su labor educativa en la promoción de hombres $\mathrm{y}$ mujeres integrales que se comprometan y participen en los procesos de transformación social. Se procura formar una persona que sea

[...] portador de valores, es decir, tolerante, respetuoso, amoroso, sensible, solidario, justo, emprendedor, participativo, productivo y competitivo, con un buen criterio de la libertad, con sentido de pertenencia y autoestima. Que tenga buenos hábitos de estudio, analítico, crítico, investigativo, creativo y abierto al cambio. Un gran líder que se involucre en la problemática de su comunidad y participe en la búsqueda de alternativas de solución a estas (Archivo reservado, p. 8).
Algunas instituciones toman las dimensiones presentadas por la CEC (antropológica, bíblica, cristológica y eclesiológica), en consecuencia, su propuesta de ERE tiene un carácter más confesional (catequesis escolar). Hay un énfasis en el desarrollo personal y comunitario dentro de la vivencia de la fe. Docentes y estudiantes coinciden en señalar la primacía de la dimensión antropológica y la naturaleza ética de la formación; los estudiantes particularizan tal opción, al referirse con insistencia al respeto, la comprensión y el amor con que son educados, representados en valores tales como el respeto mutuo y la comprensión. Se procura una formación moral, en valores cristianos y espirituales, en busca de la consolidación del sentido y proyecto de vida. Además, se reconocen las dimensiones cultural e interconfesional.

\section{Mediaciones.}

El grupo de investigación opta por las mediaciones histórico-cultural y política, como las centrales en un proceso de implementación de la ERE en perspectiva liberadora (CEC, 2000; Meza \& Suárez, 2013, p. 158). En el diálogo con las instituciones se percibe que no hay claridad en la comprensión de las mediaciones, más bien, ellas indican cómo la misma ERE es mediación para conocer la realidad, y cómo los componentes de la ERE se convierten en mediaciones.

No obstante lo cultural y lo político se hace presente. Los centros educativos aprovechan los acontecimientos del contexto para educar religiosamente. Por ejemplo, una de las instituciones busca que el estudiante piense en lo que pasa en el mundo actual, no solo en el ámbito nacional, sino también internacional. En la práctica, se valen de las fiestas culturales, las celebraciones y las expresiones de la sociedad para motivar y enseñar lo que desean. En otro de los colegios se indica que la ERE pone en diálogo crítico la fe y la vida, la fe y la cultura en contraste con otra que dice hacer una "lectura sabia de la realidad" pero las acciones de la ERE no pretenden la transformación de la cultura. 
En general, las mediaciones son comprendidas por los docentes en términos de recursos didácticos empleados para la clase (tales como audiovisuales y carteleras, en el caso de los profesores, y fotocopias de libros y diapositivas, en el caso de los estudiantes). Se reconoce también la necesidad de apropiar los recursos ofrecidos desde las tecnologías e Internet.

\section{Contenidos.}

Aunque no resulta fácil, el grupo investigador ha sugerido algunos contenidos propios de una ERE en perspectiva liberadora, ellos son: el sentido de vida, el Misterio de Dios como presencia liberadora, la fe como apertura y respuesta de acción y la cultura y la historia como lugares de liberación y encuentro con el Misterio (Meza \& Suárez, 2013, p. 165) ${ }^{4}$.

Al revisar las propuestas de las instituciones se puede decir que, en general, los contenidos se enmarcan en el desarrollo personal y el conocimiento de asuntos religiosos: la Sagrada Escritura, el catecismo, la liturgia católica, la vida sacramental y las devociones religiosas, lo que indica que se trata de una ERE confesional o catequesis escolar.

Existe una inclinación especial por conocer la vida de Jesús, el carácter social del cristianismo y la promoción de la dignidad personal. Hay un empeño importante en torno a los tiempos litúrgicos de la iglesia católica, desconociendo que no todos los estudiantes pertenecen a ella. Los estudiantes se quejan de la "repetición de contenidos" sobre todo cuando se enfatiza en las celebraciones del tiempo litúrgico.

Algunos de los contenidos apuntan hacia el proyecto de vida cristiana y el abordaje de problemas familiares tales como la drogadicción, el aborto y la prostitución. Se insiste en algunos valores y derechos humanos. También, en casi todas las instituciones, se desarrollan temas referentes al pluralismo religioso y el conocimiento de las grandes religiones.

\section{Didáctica.}

Los centros educativos participantes comprenden la didáctica como el uso de recursos en el aula de clase y no la conciben como un saber constructor de conocimiento transformador, que opta por el estudiante como sujeto social, que entiende la labor del docente como acompañante coaprendiente, que incentiva la libertad integral, que va más allá de las metodologías, que elige enfoques didácticos en los cuales la persona y su contexto social sean los ejes de problematización y aprendizaje; y que, por supuesto, acoge diversos recursos como las nuevas tecnologías y los medios de comunicación actuales (Jiménez, 2011; Meza \& Suárez, 2013, p. 171) .

El diseño didáctico de la clase es transmisionista. La clase de ERE tiene actividades y recursos que la hacen atractiva (guías, talleres, películas) pero estos no se identifican con una didáctica liberadora. Además, no se percibe el rol del maestro como coaprendiente, ni del estudiante como sujeto histórico.

Hay un eclecticismo en las nociones didácticas de la ERE y hay una gran variedad de recursos didácticos. Algunas actividades suscitan una reflexión por parte del estudiante, pero no se ve una conexión con el contexto. Además, no hay protagonismo por parte del educando ni un papel transformador. Sin embargo, resulta interesante el recurso a la religiosidad popular.

Existe una tendencia a señalar una didáctica inspirada en la pedagogía constructivista. De igual modo, el intento de abordar el trabajo de aula desde la realidad personal y social de los jóvenes en función de su proyecto de vida. En uno de los PEI se afirma que la institución apuesta por un aprendizaje significativo pero no se evidencia ni en las entrevistas, ni en el plan de área ni tampoco en los cuadernos de los estudiantes.

Se resalta en todas las instituciones el esfuerzo por hacer significativa la asignatura de la ERE, acudiendo en muchos de los casos al 
recurso lúdico. Empero, no aprovechan los elementos contextuales ni la pluralidad de su expresión religiosa para enriquecer los contenidos $\mathrm{y}$ las formas de relación con los estudiantes.

\section{Evaluación.}

Dentro de la lógica propuesta para una ERE en perspectiva liberadora la evaluación se entiende como valoración más que calificación, en la cual el estudiante sea capaz de autoagenciarse, discerniendo los avances que ha logrado en su camino formativo. Aunque no se halle a plenitud esta idea, algunos colegios tienen criterios claros sobre la evaluación, dejando que esta descanse también en las vivencias. Al respecto, la vivencia en la evaluación de la ERE tiene connotaciones liberadoras cuando en realidad existen criterios y acuerdos entre docente y estudiantes, basados en un proceso de crecimiento personal, integral y cualitativo (Freire, 2005, p. 52; Meza \& Suárez, 2013, p. 179).

Además, en las diferentes instituciones encontramos algunas nociones y prácticas evaluativas bastante conocidas. Por ejemplo, la verificación del aprendizaje de contenidos (memorización de conceptos y datos) como forma de "dar razón de la fe". También prima la heteroevaluación. Es el profesor quien determina la consecución de los objetivos y la calidad del trabajo desarrollado. Se podría decir, que la evaluación es tradicional, no se nota un proceso o un cambio del modo clásico de valorar las asignaturas, donde la calificación es la que marca las relaciones del proceso enseñanza-aprendizaje en la enseñanza de la ERE. En uno de los colegios se enuncian indicadores de desempeño para cada uno de los periodos académicos; no obstante, no se percibe fácilmente el nexo entre tales indicadores, los estándares, las competencias registradas y lo que ocurre en la práctica.

\section{Comunidad educativa.}

Uno de los fundamentos de la ERE en perspectiva liberadora, es la integración de la comunidad educativa porque esta es el escenario en el cual se da el proceso de enseñanza-aprendizaje, es el lugar de liberación en donde ocurre la experiencia integral de vida (Meza \& Suárez, 2013, p. 184; Freire, 2001, p. 73). Sin embargo, el análisis realizado nos permitió constatar que esta integración es nominal. Se dice de la responsabilidad social que posee la comunidad en función de transformar los ambientes de opresión de los estudiantes y las condiciones sociales de pobreza. En general, se identifica la relación entre los actores de la escuela y de esta con la comunidad, pero no se observan acciones recurrentes y procesuales.

Con todo, en los profesores hay una comprensión de lo que significa la comunidad educativa, no así en los estudiantes. En uno de los centros educativos de Nariño se concibe la importancia de la comunidad educativa en el proceso de enseñanza-aprendizaje. En otras se sostiene que el estudiante es el centro del proceso educativo, el padre es el primer responsable en su acompañamiento y el maestro es un mediador. El padre de familia se vincula al proceso de formación de su hijo como directo responsable de esta y conocedor de todo aquello que sucede al interior de la institución.

Uno de los colegios de Putumayo dedica un amplio apartado en el PEI para describir a cada uno de los miembros de la comunidad educativa y sus responsabilidades para con los estudiantes. Sin embargo, se perciben relaciones verticales y unidireccionales entre profesores y directivas hacia los estudiantes y sus padres. En una de las instituciones de Nariño, aunque considera relevante la vinculación con el contexto, se advierte cierto temor hacia el "trabajo de campo" o actividades que puedan efectuar los estudiantes en los diferentes barrios del municipio. Se argumenta que la violencia en la región es una realidad que no se pude negar. Más aún, una de las profesoras señaló que "la escuela está enjaulada". 
Finalidad.

El área de ERE busca el desarrollo integral de la persona y la promoción de la dimensión religiosa (trascendental, espiritual o de sentido) en relación con la cultura y la sociedad. No obstante, como ya se señaló en la primera parte de este artículo, la ERE liberadora va más allá porque busca la concienciación del sujeto para que de manera crítica y responsable pueda deconstruir aquello que lo aliena religiosamente (mitos, creencias, ritos, códigos, costumbres) y resignificarlo como clave de sentido para transformar la realidad en la cual se encuentra con los otros (Meza \& Suárez, 2013, p. 123; Preiswerk, 1994, p. 46).

El estudio realizado nos permitió constatar que las instituciones se preocupan por una formación integral que considera la dimensión espiritual y el desarrollo de las diferentes facultades del ser humano. Empero, la "formación integral" se considera de distintas maneras a la hora de pensar la contribución que recibe de la ERE: la tendencia a relacionar la finalidad de la ERE con la conservación de la confesionalidad o catolicidad de la cultura, el deseo de que los estudiantes sean "hombres y mujeres de bien", la necesidad de tener "bonita relación con Dios", la construcción del sentido de vida, el conocimiento profundo de Dios y de la iglesia y la formación de hombres y mujeres comprometidos con Dios, mediante una honda experiencia espiritual, personal y comunitaria, vivida desde los valores del Evangelio.

En alguna de las instituciones los estudiantes afirmaron que la clase de ERE es para "mejorar sus sentimientos y se puedan acercar más a Dios a través de la formación en la fe y la esperanza". En otra, un estudiante señaló que la ERE es para "tener otras visiones de lo que es la religión y no encasillarse en una sola". Otro estudiante apuntó que esta área es para que "les vaya bien en la vida y no tengan tropezones". Creemos que lo anterior queda recogido en este objetivo encontrado en uno de los programas de área:
La ERE busca que el estudiante identifique los principios y valores de la fe cristiana, desarrolle actitudes y comportamientos personales coherentes con la fe cristiana, participe en actividades religiosas en forma individual y comunitaria; y sea capaz de comprometerse con el rescate, promoción y vivencia de auténticos valores humanos, tales como el respeto por la vida humana y por la familia, la justicia, la libertad y la paz, motivado por la fe (Archivo reservado, p.2).

Lo hallado nos permite concluir que aún persiste una escisión entre la fe y la vida, la formación religiosa y la formación política, entre el proyecto de vida personal y el proyecto comunitario (y de nación), entre una actitud creyente pasiva que espera y una actitud creyente activa que transforma, entre las concepciones religiosas ingenuas y las miradas críticas de la religión.

\section{Legitimación.}

Recordemos que el enfoque de legitimación se entiende como el referente de justificación de la educación religiosa en la escuela (Meza, 2011, p. 24; Salas, 1993). A nuestro modo de ver la legitimación puede poner su acento en el ser humano (legitimación desde lo antropológico), la iglesia (legitimación desde la misión de la iglesia) o la cultura (legitimación desde la función y aporte de la religión en la cultura y la sociedad). Sin embargo, resulta interesante haber hallado que las instituciones legitiman la ERE a partir de algunos de estos referentes (la iglesia católica y el ser humano) pero también de otros (la realidad social y la legislación en nuestro país).

Legitimación desde la iglesia católica: para varias instituciones, el referente primero de la ERE es la iglesia y la pertenencia de muchos a la fe católica. Los estudiantes consideran que la clase de religión se legitima por la confesionalidad del colegio y resaltan que no hay discriminación frente a otras doctrinas cristianas. 
Legitimación desde el ser humano: para algunos colegios el área de educación religiosa es importante porque permite al estudiante la reflexión, propicia la búsqueda del sentido de la vida y su trascendencia, fortalece la formación en valores, reafirma su identidad, cultiva las formas de acercamiento, conocimiento y expresión de la experiencia religiosa, y hace que asuma con criterio su proyecto de vida.

Legitimación desde la realidad social: una de las instituciones de Bolívar cree que la ERE prepara para afrontar la compleja situación del país. Los estudiantes reconocen que la asignatura los lleva a tener actitudes solidarias con los demás. Los referentes de legitimación antropológica y cultural apenas se perciben.

Legitimación desde la legislación: uno de los colegios de Nariño estima que la ERE existe y ocurre como cumplimiento a un marco jurídico nacional que favorece la libertad de cultos, promueve el deseo que pueda tener una comunidad educativa por una formación religiosa y respeta la libertad que tienen los ciudadanos para no recibir una educación religiosa.

\section{Objeto de estudio.}

La ERE liberadora considera a la persona, sujeto y protagonista de su propio proceso de emancipación, en relación con los otros y el Misterio, como su objeto de estudio (Meza \& Suárez, 2013, p. 135; Peresson, 2004). Con este presupuesto no se encontraron mayores evidencias. Por el contrario, las instituciones identificaron los siguientes objetos de estudio de la ERE: contenidos religiosos (conceptos, ideas, costumbres), experiencias religiosas (vivencias, acontecimientos de fe), el hecho religioso (expresiones, iglesias y grupos religiosos), la dimensión religiosa, los valores y Dios (la vida de Jesucristo, la Sagrada Escritura y Dios mismo). En general, no hay referencia a la persona como sujeto de liberación ni a la comunidad como lugar de liberación.

\section{Integración curricular.}

Una ERE en perspectiva liberadora, tiene claridad sobre las relaciones dentro del plan curricular, para ofrecer su saber crítico-liberador al proceso de formación integral y aportar a la construcción interdisciplinaria del conocimiento de cara a la realidad. La investigación constata que existen intentos de correlación entre los temas de la ERE con los de otras áreas, lo cual posibilita el aporte desde los diferentes saberes. Con respecto a la integración curricular, las instituciones la entienden de tres modos:

- Integración de algunos temas o contenidos que son comunes a algunas áreas: como las ciencias naturales, por la preocupación por el asunto de la ecología; las ciencias sociales, en lo atinente a la formación ciudadana, la comprensión del hecho religioso y la construcción de una comunidad democrática en el orden étnico, regional, religioso e ideológico; y las ciencias humanas, sobre el proyecto de vida y el respeto a la dignidad humana. Algunas instituciones evidencian el interés por abordar de forma transversal temas que se conectan con la vida, el sentido de la vida, la familia, la comunidad y la cultura como nivel de desarrollo social, intelectual y artístico.

- Integración desde actividades de orden litúrgico: en este modo se tiende a relacionar la ERE solo con la religión, por eso, se habla de vincular el área con las celebraciones religiosas y las prácticas de piedad.

- Integración con áreas específicas: como la ética y la formación ciudadana, particularmente en el aspecto axiológico porque todas ellas buscan la "sana convivencia".

Las instituciones son conscientes de que ninguna hace una apuesta por un proceso libe- 
rador desde su propuesta curricular. No existe una integración real entre las áreas; solo alguna relación con respecto a temas comunes. Prevalece un currículo fragmentado e independiente en donde la ERE es una asignatura de segundo orden y su cometido es responsabilidad de los profesores del área. En el plan de estudios no se menciona la existencia de proyectos transversales.

\section{Conclusiones}

La lectura analítica de la ERE en las instituciones participantes nos permite afirmar que, si bien algunos de sus elementos se aproximan a una perspectiva liberadora, son solo atisbos. Los datos identificados en los diversos documentos institucionales (PEI, plan de área y programas de asignatura) tendrían mayor cercanía que aquellos observados en la puesta en marcha. De hecho, las características de "la clase de religión" se perciben con poca diferencia a las que había años atrás. Es una asignatura marcada por lo confesional, con contenidos propios del catolicismo, centrada en la memorización de datos, con una didáctica más pasiva que activa, dentro de una relación asimétrica profesorestudiante, con una evaluación más heterónoma que autónoma, que olvida la realidad religiosa plural de su contexto y, por lo tanto, no aprovecha intensamente los recursos que tiene a su disposición.

Además, la apuesta por la formación integral, categoría presente en los documentos de todas las instituciones, debería caracterizarse, entre otras cosas, por promover la dimensión religiosa encarnada en la cultura. De esta forma, no se trata de una relación intelectiva o pasiva, antes bien supone una comprensión de la realidad religiosa por parte de la persona (como ser inteligente, sentiente y actuante) con una actitud reflexiva, analítica y crítica. Fruto de ello será, entre otros, el encuentro con el Misterio para la búsqueda de sentido, el encuentro con los otros como clave de humanización y el encuentro con el mundo con un propósito performativo. En otras palabras, una institución que le apuesta a una ERE liberadora promueve la religación entre Dios-ser humano-mundo.

Una ERE liberadora potencializa lo que las diversas instituciones han hecho explícito en sus diseños de educación religiosa: formar mujeres y hombres de valores sólidos inspirados en el Evangelio (justicia, perdón, paz, caridad y esperanza) y, por tanto, ciudadanos que advierten que, para alcanzar la justificación, es necesario pasar por la justicia; no hay salvación sin liberación; lo trascendente se logra a través de la inmanencia.

Una ERE liberadora encierra en su finalidad la concienciación del sujeto, su liberación, su humanización, la opción por el pobre, la valoración de su propia cultura y de su historia, como condición de una experiencia religiosa auténtica (Suárez et al., 2013, p. 227). Una ERE liberadora promueve la concientización del sujeto para que sea capaz de ver la experiencia del oprimido -incluso si él también lo es- y de los mecanismos sociales que generan opresión, pero también de su compromiso para transformar tal realidad.

Luego del camino recorrido creemos que Colombia está en mora de establecer unas políticas claras y unos lineamientos consistentes con respecto a la ERE. Algunas propuestas de ERE son excluyentes, otras demasiado vagas. Quizá se ha querido que cada institución solucione el problema como mejor pueda. En algunos casos se ha cambiado la ERE de la institución por otro tipo de formación (ética, axiológica o ciudadana). Pero, nada de lo anterior debería ocurrir y menos como un signo de improvisación. Es hora de pensar la ERE y, por qué no, desde un propósito liberador.

\section{Notas}

${ }^{1}$ Resulta significativo el número de libros y artículos divulgados en lengua inglesa. A manera de ilustración podemos traer a colación 
algunos trabajos publicados en la última década, en los cuales se pide repensar la educación religiosa en un mundo cada vez más plural y su presencia en una escuela laica. Además, en ellos aparece una reflexión acerca de la relación de la educación religiosa con el secularismo, la formación ciudadana, la ética, los valores y la espiritualidad. Algunos son: Broadbent y Brown (2002), Gearon (2004); Jackson (2004) y MacMullen (2007).

${ }^{2} \mathrm{Si}$ bien es cierto que usamos con frecuencia la palabra "concientización", Freire la diferencia de "concienciación", ya que para él esta es el resultado de un proceso que ha ocurrido al interior del sujeto. Es la persona quien ha ganado "conciencia de su sí mismo, de su realidad" gracias a una experiencia endógena. El lector sabrá reconocer este sentido en el uso dado a los dos términos (Suárez et al., 2013, p. 227).

${ }^{3}$ Los nombres de las instituciones son: Colegio Cristo Rey, Cúcuta (Norte de Santander), Colegio Departamental Integrado Juan Atalaya, Cúcuta (N. de Santander), Colegio Mariano Ospina Rodríguez, Cúcuta (N. de Santander), Institución Educativa Ciudad de Asís, Puerto Asís (Putumayo), Institución Educativa Técnico Agropecuario y Comercial Eutimio Gutiérrez Manjón, Simití (Bolívar), Institución Educativa del Sur (Insur), Ipiales (Nariño), Institución Educativa María Luz, Imués (Nariño), Institución Educativa Misional Santa Teresita, Tumaco (Nariño), Institución Educativa Nuestra Señora del Pilar, Villagarzón (Putumayo), Institución Educativa Pío XII, Mocoa (Putumayo), Institución Educativa Politécnico Marcelo Miranda, Ipiales (Nariño), Institución Educativa Ricaurte, Ricaurte (Nariño), Institución Educativa San Lorenzo de Yaramal, Ricaurte (Nariño) e Institución Educativa Técnico Agropecuario y Comercial Alfredo Nobel, Santa Rosa del Sur (Bolívar). (2000).

${ }^{4}$ Confróntese Arquidiócesis de Bogotá

${ }^{5}$ Confróntese CEC (1997).

\section{Referencias}

Arellano, N. (2010). El método de investigación acción crítica reflexiva. Recuperado de http://www.scribd.com/doc/7061166/ Arellano-N-El-Metodo-de-InvestigacionAccion-Critica-Reflexiva.

Arquidiócesis de Bogotá., \& Secretaría de Educación del Distrito Capital. (2000). Orientaciones curriculares para la educación religiosa en el Distrito Capital. Bogotá: Autor.

Bandera, A. (1991). Paulo Freire. Un pedagogo. Caracas: Universidad Andrés Bello.

Bellett, E. (1998). Religious Education for Liberation: A Perspective from Paulo Freire. British Journal of Religious Education, 20(3), 133-143.

Boff, C. (1990). Epistemología y método de la teología de la liberación. En I. Ellacuría \& J. Sobrino (Eds), Mysterium liberationis. Conceptos fundamentales de la teología de la liberación (pp. 79-113). Madrid: Trotta.

Boff, L., \& Muraro, R. (Eds.) (2004). Conciencia y transformación. En Femenino y masculino. Una nueva conciencia para el encuentro de las diferencias (pp. 177183). Madrid: Trotta.

Broadbent, L., \& Brown, A. (2002). Issues in Religious Education. Londres: Routledge Falmer.

Conferencia Episcopal de Colombia [CEC]. (1997). Guía para el desarrollo de los contenidos de la enseñanza religiosa escolar en los niveles de básica secundaria y media. Bogotá: Autor.

Conferencia Episcopal de Colombia [CEC]. (2000). Escuela y religión. Hacia la cons- 
trucción de un modelo de educación religiosa. Bogotá: Autor.

Fals-Borda, O. (1978). Por la praxis: el problema de cómo investigar la realidad para transformarla. Trabajo presentado en la Conferencia Mundial de Cartagena, Crítica y política en ciencias sociales, Cartagena.

Fals-Borda, O. (1992). La ciencia y el pueblo: nuevas reflexiones. En M. C. Salazar (Ed.), La investigación-acción participativa. Inicios y desarrollo (pp. 65-84). Madrid: Editorial Popular; OEI.

Freire, P. (Ed.) (1989). La alfabetización como elemento de formación ciudadana. En Política y educación (pp. 9-39). México: Siglo XXI Editores.

Freire, P. (2001). Politica y educación. México: Siglo XXI Editores.

Freire, P. (2005). La importancia de leer y el proceso de liberación. Buenos Aires: Siglo XXI.

Freire, P. (2010). Cartas a quien pretende enseñar. Buenos Aires: Siglo XXI.

Garcés, E., García, G., \& Medarda, L. (1998). Claves curriculares de la reforma. Madrid: Promoción Popular Cristiana.

Gearon, L (2004). Citizenship through Secondary Religious Education. Londres: Routledge Falmer.

Hurtado, I. (1998). Paradigmas y Métodos de Investigación en tiempos de cambio $\left(2^{\mathrm{a}}\right.$ ed.). Valencia: Episteme.

Jackson, R (2004). Rethinking Religious Education and Plurality. Issues in diversity and pedagogy. Londres: Routledge Falmer.
Jiménez, J. R. (2011). Didáctica de la ERE. En J. L. Meza (Dir.), Educación religiosa escolar. Naturaleza, fundamentos $y$ perspectivas (pp. 295-324). Bogotá: San Pablo.

Ley 115 de 1994. Por la cual se expide la ley general de educación. Diario oficial No. 41.214. Congreso de la República de Colombia, febrero de 1994.

Lewin, K. (1992). La investigación-acción y los problemas de las minorías. En M. C. Salazar (Ed.), La investigación-acción participativa. Inicio y desarrollo $\left(6^{\mathrm{a}}\right.$ ed.) (pp. 13-25). Madrid: Biblioteca de Educación de Adultos.

MacMullen, I (2007). Faith in Schools? Autonomy, Citizenship and Religious Education in the Liberal State. Nueva Jersey: Princeton University Press.

Meza, J. (Dir.) (2011). Educación religiosa escolar. Naturaleza, fundamentos y perspectivas. Bogotá: San Pablo.

Meza, J., \& Suárez, G. (Dirs.) (2013). Educar para la libertad. Una propuesta de educación religiosa escolar en perspectiva liberadora. Bogotá: San Pablo.

Panini, J., \& Hidalgo, P. H. (1975). Educación liberadora. Dimensión pastoral. Bogotá: Editorial Stella.

Peresson, M. (2004). Evangelizar educando desde las áreas del currículo. Bogotá: Kimpres.

Preiswerk, M. (Ed.) (1994). Apuntes sobre la educación popular. En Educación popular y teología de la liberación (pp. 3165). San José de Costa Rica: DEI.

Salas, A. (1993). Didáctica de la enseñanza de la religión. Madrid: CCS. 
Sanz, J. J. (1985). Educación y liberación en América Latina. Bogotá: Universidad Santo Tomás.

Segunda Conferencia General del Episcopado Latinoamericano. (1968). Documento de Medellín. Medellín: Autor. Recuperado de http://www.ensayistas.org/critica/liberacion/medellin/medellin6.htm
Suárez, G., Meza, J. L., Garavito, D., Lara, D., Casas, J. A., \& Reyes, J. O. (2013). Educación religiosa escolar en clave liberadora: elementos constitutivos. Theologica Xaveriana, 175, 219-248.

Torres, F. (Ed.) (1999). Subjetividad: abriendo caminos. En Por caminos propios: Construcción pedagógica de la teología popular (pp. 105-145). Bogotá: Dimensión educativa. 